\title{
Cardioprotective Effect of Quercetin and Sitagliptin in Doxorubicin-Induced Cardiac Toxicity in Rats
}

This article was published in the following Dove Press journal:

Cancer Management and Research

\author{
Tavga Ahmed Aziz $\mathbb{D}$ \\ Department of Pharmacology and \\ Toxicology, College of Pharmacy, \\ University of Sulaimani, Sulaimani City, \\ Iraq
}

Objective: A previous study revealed a pronounced protective effect of combining quercetin (QC) with sitagliptin (STN) in testicular tissue. Accordingly, this study was designed to evaluate the cardioprotective effects of QC and STN each alone or in combination in doxorubicin (DOX)-induced cardiotoxicity in the rats.

Methodology: Thirty male adult Wistar rats were divided into five groups: the first group (control) treated with sodium chloride, the second group treated with DOX $(3 \mathrm{mg} / \mathrm{kg} \mathrm{I}$. P. injection), the third group treated with DOX with a combination of QC $(80 \mathrm{mg} / \mathrm{kg})$, and STN $(10 \mathrm{mg} / \mathrm{kg})$, the fourth group treated with DOX and QC and the fifth group treated with DOX and STN. Blood was collected on day 22 and used for assessment of serum troponin, lactate dehydrogenase $(\mathrm{LDH})$, creatine phosphokinase (CPK), total lipid profile, C-reactive protein (CRP), and total antioxidant capacity (TAOC). Atherogenic indices were also calculated. Cardiac tissue was sent for histopathological analysis.

Results: DOX produced a significant increase in the level of troponin, LDH, CKP, CRP, total cholesterol (TC), low-density lipoprotein (LDL), triglycerides (TG), and atherogenic index of plasma; and significantly decreased TAOC. The combination of quercetin and sitagliptin was more effective than each treatment alone in restoring the level of troponin, LDH, CKP, CRP, Cholesterol, LDL, TG, atherogenic index of plasma and significantly increased TAOC compared to DOX treated group. The histopathological finding also supports the biochemical results.

Conclusion: The study revealed the cardioprotective effects of the combination of QC and STN which could be attributed to the additive effects of this combination through antioxidant, anti-inflammatory, lipid lowering and anti-atherogenic activities; suggesting it as a good therapeutic candidate to be tested in the clinical setting.

Keywords: cardiotoxicity, doxorubicin, quercetin, sitagliptin, rats

\section{Introduction}

Cardiovascular diseases (CVD) are a serious health problem and one of the most leading causes of morbidity and mortality in the world. ${ }^{1}$ Cardiotoxicity induced by medications is one of the most important adverse reactions that may halt the use of many newly discovered medications and lead to the discontinuation from clinical trials and it could result in withdrawal from the market when it produced serious side effects. ${ }^{2}$ Most of the drug classes may have cardiotoxic effects but these effects appear only after prolonged use of these medications; for instance, anticancer agents may represent a major class of drugs that cause cardiac damages either by the parent compound or its metabolite. ${ }^{3}$ Doxorubicin is an anthracycline antibiotic, very effective in the treatment of various types of cancer, but the development of
Correspondence: Tavga Ahmed Aziz Tel +964770I523544

Email tavga.aziz@univsul.edu.iq
Cancer Management and Research 2021:13 2349-2357 in $\mathbf{D}$ 
cardiac damage may attenuate its clinical uses. The cardiac toxicities of doxorubicin include transient cardiac arrhythmia, ECG changes, cardiomyopathy, and acute heart failure. ${ }^{4}$ Two main theories explain the mechanisms of doxorubicin-induced cardiotoxicity; mitochondrial disruption and iron-generated free radicals. ${ }^{5}$ Despite signs of progress in CVD treatment, it is still the leading cause of death, thus, the main approach recently is toward the prevention of CVDs. ${ }^{6}$ Therefore, new treatment options are greatly recommended for all types of CVDs. Nutraceuticals have been used for the management of various diseases, either in the form of plant extracts or as pure active compounds. ${ }^{7}$ Cardioprotective effects of many plants have been broadly studied, ${ }^{1}$ like ginkgo biloba extract, ${ }^{8}$ grape seed proanthocyanidins, ${ }^{9}$ and sour cherry seed kernel. ${ }^{10-12}$ Among dietary flavonols, quercetin is present in many fruits and vegetables and has gained great attention because of its anti-inflammatory and anti-oxidant activities. ${ }^{13}$ Various studies showed the involvement of quercetin in decreasing mortality from cardiovascular diseases through its vasodilator, antioxidant, and antiaggregatory effects. ${ }^{13,14}$ The antihyperglycemic agent, dipeptidyl peptidase-4 inhibitors, has been broadly used recently; ${ }^{15}$ it acts through restoring the level of glucagonlike peptide 1(GLP-1) and gastric inhibitory peptide (GIP) that control the level of glucose. ${ }^{16}$ This drug has been verified for its efficacy and safety in many clinical trials. The safety of sitagliptin on the cardiovascular system also has been proved. ${ }^{17}$ Neither the risk of cardiovascular nor type 2 diabetes mellitus complications were reported upon the use of sitagliptin. ${ }^{18}$ The drug was also shown to be effective in decreasing the incidence of cardiovascular events in diabetic patients. ${ }^{19}$ Both quercetin and sitagliptin showed a cardioprotective effect; ${ }^{13,17}$ however, their combination did not have been searched yet in the cardiovascular system. Accordingly, the present study was designed to evaluate the cardioprotective effects of quercetin and/or sitagliptin alone or in combination with doxorubicininduced cardiotoxicity in the rat.

\section{Materials and Methods}

Thirty male adult Wistar rats, weighing 200-250 g, were purchased from the animal house of the University of Sulaimani and kept well-ventilated plastic cages, at an ambient temperature $25 \pm 2{ }^{\circ} \mathrm{C}$ and humidity of $55 \pm 5 \%$ under $12 \mathrm{hr}$ dark-light cycle for 1 week before the experiment. Experimental protocols met the Guidelines for Animal Experimentation and approved by the Ethical
Committee of the University of Sulaimani (Certificate no. 8 on 28th April 2019) following the institutional Animal Ethics Committee. The study was performed in accordance with the Canadian Council on Animal Care (CCAC) guidelines, 1998. The rats were fed standard laboratory chow with water ad libitum. All animals were randomly divided into five groups; the doses and the route of administrations of each treated group have been chosen depending on the previous study. ${ }^{20}$ The groups comprise six animals each as follows:

- Group I: Control group: Treated with $1 \mathrm{~mL}$ of $0.9 \%$ sodium chloride orally by gavage tube on days 8,10 , $12,15,17$, and 19 from the start of the study.

- Group II: Doxorubicin (DOX) treated group: Received DOX I.P.injection ( $3 \mathrm{mg} / \mathrm{kg}$ ) on days 8 , $10,12,15,17,19$ from the start of the study. This treatment protocol was applied for all groups except for the control group.

- Group III: Treated with quercetin (QC) $80 \mathrm{mg} / \mathrm{kg}$ with sitagliptin (STN) $10 \mathrm{mg} / \mathrm{kg}$ both given orally by gavage tube daily for 21 days with the DOX treatment protocol.

- Group IV: Treated with QC $80 \mathrm{mg} / \mathrm{kg}$ given orally by gavage tube daily for 21 days with the DOX treatment protocol.

- Group V: Treated with STN $10 \mathrm{mg} / \mathrm{kg}$ given orally by gavage tube daily for 21 days with the DOX treatment protocol.

\section{Biochemical Parameters}

Blood was collected by cardiac puncture at the end of the study on day 22; the blood centrifuged and sera were separated and used for assessment of serum troponin using ELISA kit (Elabscience, Houston, TX, USA) according to the manufacturer's instructions, lactate dehydrogenase (LDH) and creatine phosphokinase (CK) were measured using kits supplied by Sigma Aldrich Co., C-reactive protein (CRP) evaluated using an enzymelinked immunosorbent assay kit (Elabscience, Houston, TX, USA) according to the manufacturer's instructions. Total antioxidant capacity (TAOC) was measured using assay kits purchased from Elabscience, USA, according to the manufacturer's protocol. Total lipid profile (TC, TG, LDL, and HDL) was also determined colorimetrically using ready-made kits (Randox, London, UK) according to the manufacturer's instructions. 


\section{Determination of Atherogenic Indices}

The atherogenic indices were calculated as follows: ${ }^{21,22}$

Atherogenic index in plasma $=\log ([$ Triglycerides $] /$ [HDL cholesterol])

Cardiac risk ratio $=[$ Total cholesterol $] /[\mathrm{HDL}$ cholesterol $]$

\section{Histotechnique Protocol}

Following animal scarification, the whole hearts were removed and cut into two slices, then cleaned from blood and epicardial fat tissue. Thereafter, heart slices were immobilized in plastic tissue cassettes and fixed in $10 \%$ neutral buffered formalin for no less than $48 \mathrm{hr}$. Heart tissues were processed into dehydration using four series changes of ascending concentration of ethanol alcohol $(60 \%, 70 \%, 90 \%$, and $100 \%)$. Afterward, tissue samples were cleaned with xylene and embedded in paraffin; the tissue-wax blocks were trimmed and sectioned to $5 \mu \mathrm{m}$ using a semi-automated microtome (Leica-Germany). Furthermore, tissue sections were mounted and fixed on glass slides using a hot water bath and dried with a hot plate for 30 minutes. Later on, heart sections were deparaffinized by dipping into two changes of xylene each for 5 minutes and then rehydrated with four descending concentrations of ethanol $(100 \%, 90 \%, 70 \%$, and $60 \%)$ each for 5 minutes as well. Finally, tissue sections were stained with Harris's hematoxylin and eosin (H\&E) technique, then as last step sections were cleaned with xylene, dried, and covered by glassy cover-slips using mounting medium Distrene-Plasticizer Xylene (DPX).

\section{Semi-Quantitative Histological Assay}

As a semi-quantitative morphometric measure, heart tissues were examined using a light microscope image analyzer under high power 400X magnifications. Briefly, histopathological lesions of fatty infiltration within the myocardial muscle tissue in addition to vascular congestion were evaluated and measured in $\mu \mathrm{m}$ and statistically assessed as a mean percentage. Whereas inflammatory cells together with myocardial degenerative cells were counted in a total of 10 fields randomly chosen under high power magnification $(1000 \mathrm{X})$, then the mean average was calculated statistically in percentage. Tissue samples were analyzed under the light microscope (Olympus BX51, Japan) using an image analyzer (AmScope 3.7, for a digital camera, MU300, 2019). Finally, the morphometric quantitative mean percentage evaluation was estimated using the following lesion score-grade values (score $0-10 \%$ as no lesions; score $10-25 \%$ as mild; score $25-75 \%$ as moderate; score $75-100 \%$ as severe lesions).

\section{Statistical Analysis}

The statistical analysis was performed using GraphPad Prism7. The values of the measured parameters were expressed as mean \pm standard deviation (S.D.). For the comparisons between different groups, one-way analysis of variance (ANOVA), followed by Bonferroni multiple comparison tests were used. The results were considered statistically significant when the p-value was less than 0.05

\section{Results \\ Effect of Quercetin and/or Sitagliptin on Serum Level of Troponin, CPK, and LDH} In the DOX-treated group, DOX produced a significant increase $(P$-value $<0.001)$ in the level of troponin compared with the control group (47.93 \pm 7.7 vs 5.8 $\pm 0.84)$. The combination of QC with STN resulted in a significant $(P$-value $=0.007)$ decrease compared to the DOX group (13.65 \pm 3.78 vs $47.93 \pm 7.7)$. Each of QC and STN alone also significantly $(P$-value $=0.081)$ and $(P$-value $=0.016)$, decreased the level compared to DOX group ( $23 \pm 3.9$ vs $47.93 \pm 7.7)$ and $(22.32 \pm 3.9$ vs 47.93 \pm 7.7 ) respectively (Figure 1A). Regarding CPK level DOX resulted in a non-significant increase $(P$-value $=0.1)$ compared to the control group, while the combination of QC and STN significantly $(P$-value $=0.01)$ decreased the level compared to DOX treated group (139 \pm 5 vs $388.7 \pm 61.6)$ (Figure 1B).

Additionally, DOX produced a significant increase $(P$-value $=0.008)$ in the level of LDH compared to the control group (222.4 \pm 32.58 vs $103 \pm 11.78)$, and the use of the QC and STN combination resulted in a significant decrease $(P$-value $=0.0029)$ compared to the DOX group (79.8 \pm 8 vs $222.4 \pm 32.58)$. Meanwhile, STN alone also produced a significant $(P$-value $=0.018)$, decrease in the levels of LDH almost comparable with that produced by the control group $(103.4 \pm 23.84$ vs $222.4 \pm 32.58)$ in comparison with DOX group. The use of quercetin alone resulted in a non-significant $(P$-value $=0.06)$ decrease $(136.2 \pm 32.5$ vs $222.4 \pm 32.58)$ in $\mathrm{LDH}$ level compared to DOX treated group (Figure 1C). 


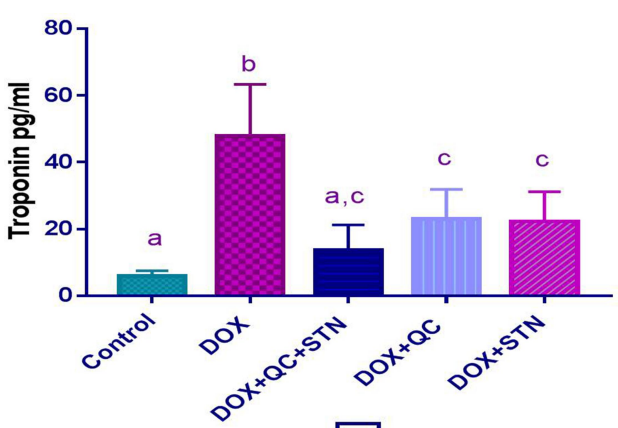

A

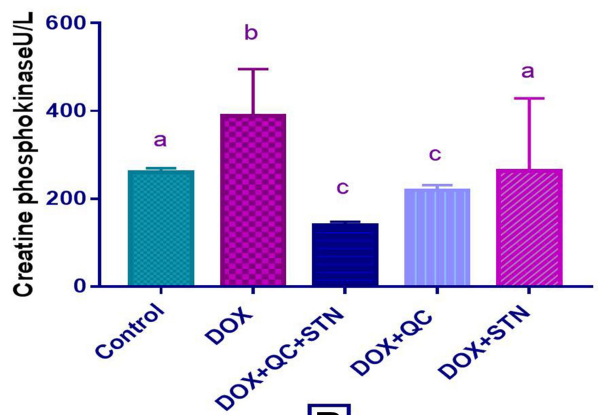

B

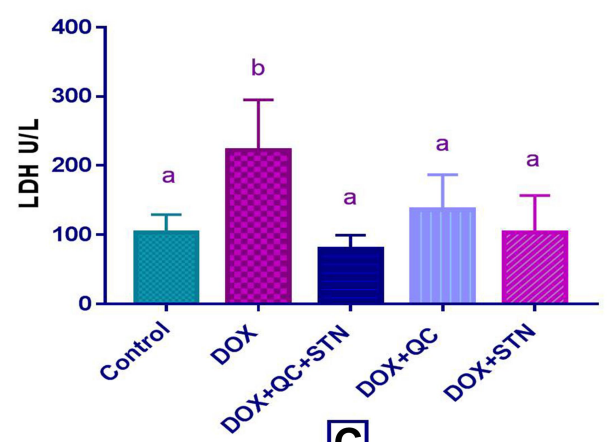

C

Figure I Effect of quercetin and/or sitagliptin on serum level of $(\mathbf{A})$ troponin, $(\mathbf{B})$ CPK and $(\mathbf{C}) \mathrm{LDH}$. Values were presented as mean \pm S.D ( $\mathrm{n}=6$ animals in each group); values with non-identical letters $(a, b, c)$ are significantly different using ANOVA and post hoc test $(p<0.05)$.

\section{Effect of Quercetin and/or Sitagliptin on Serum Level of CRP and TAOC}

DOX resulted in a non-significant increase $(P$-value $=0.1)$ in the level of CRP compared to the control group, while the combination of QC and STN significantly $(P$-value $=0.005)$ decreased the level compared to DOX treated group $(0.17 \pm$ 0.005 vs $0.23 \pm 0.01$ ) (Figure 2A). Furthermore, significant $(P$-value $<0.0001)$ decrease in TAOC observed in the DOX-treated group compared to the control $(0.022 \pm 0.002$ vs $0.108 \pm 0.003)$. Combination of QC and STN significantly $(P$-value $=0.0003)$ increased the level of TAOC

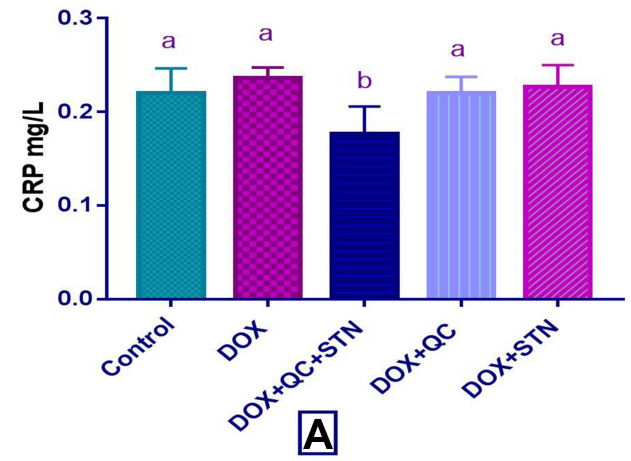

$(0.126 \pm 0.01$ vs $0.022 \pm 0.002)$. The use of QC alone also achieved a significant increase compared to DOX group $(0.11 \pm 0.004$ vs $0.022 \pm 0.002)$ (Figure 2B).

\section{Effect of Quercetin and/or Sitagliptin on Serum Lipid Profile and Atherogenic Indices}

The use of DOX revealed a significant $(P$-value $=0.004)$ increase in the level of total cholesterol compared to the control group $(132 \pm 4.3$ vs $103.3 \pm 2)$. Only QC treated group significantly $(P$-value $=0.013)$ decreased the level

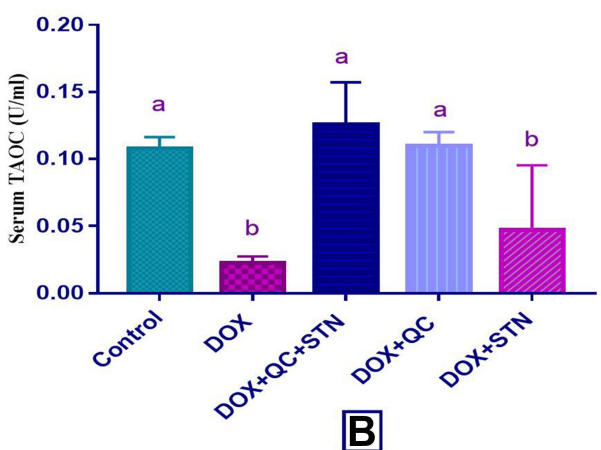

Figure 2 Effect of quercetin and/or sitagliptin on serum level of (A) CRP and (B) TAOC. Values were presented as mean \pm S.D ( $n=6$ animals in each group); values with non-identical letters $(a, b)$ are significantly different using ANOVA and post hoc test $(p<0.05)$. 
compared to DOX treated group $(113.7 \pm 0.3$ vs $132 \pm 4.3)$ (Figure 3A). Moreover, LDL level also increased significantly $(P$-value $=0.01)$ by DOX compared to control group $(69 \pm 2$ vs $36 \pm 3.5)$. The combination of QC and STN and the use of each

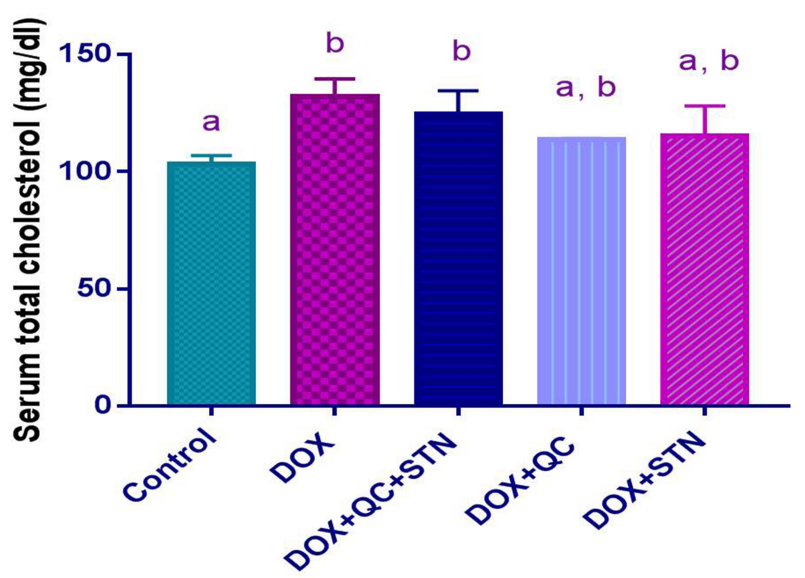

A

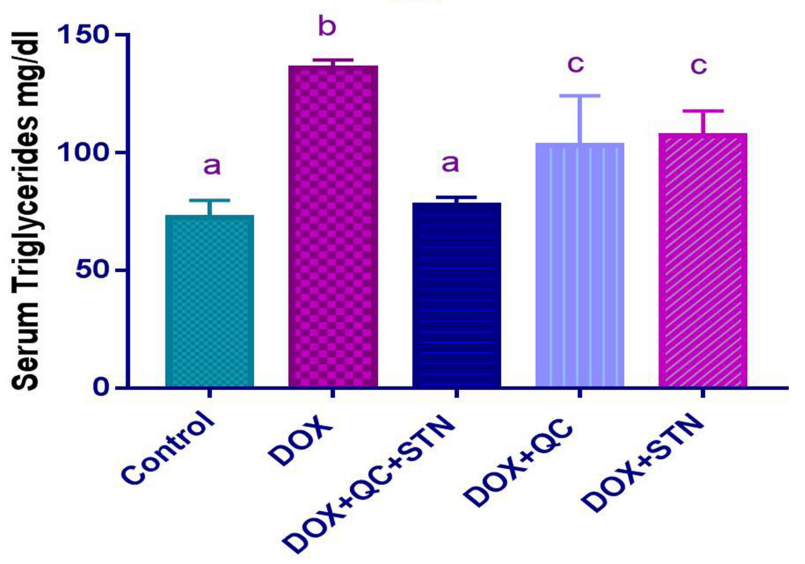

C

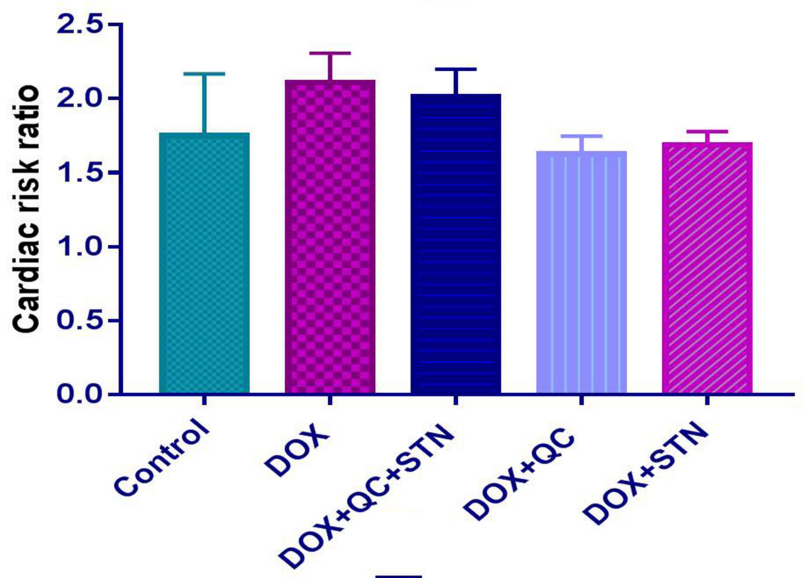

国 of QC and STN alone resulted in a significant $(P$-value $=0.03)$ decrease of LDL level compared to DOX treated group (47 7 vs $69 \pm 2),(42.5 \pm 2.5$ vs $69 \pm 2)$ and $(46.6 \pm 0.65$ vs $69 \pm 2)$ respectively (Figure 3B). Serum TG level was significantly

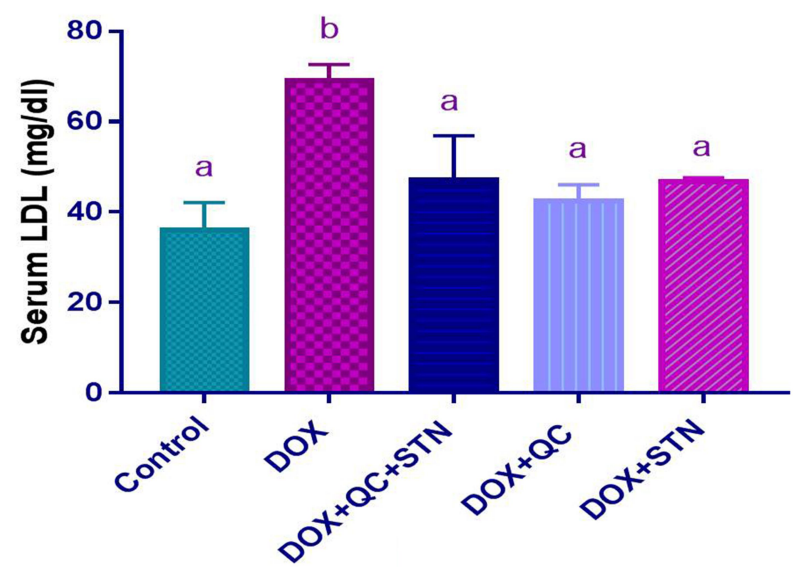

B

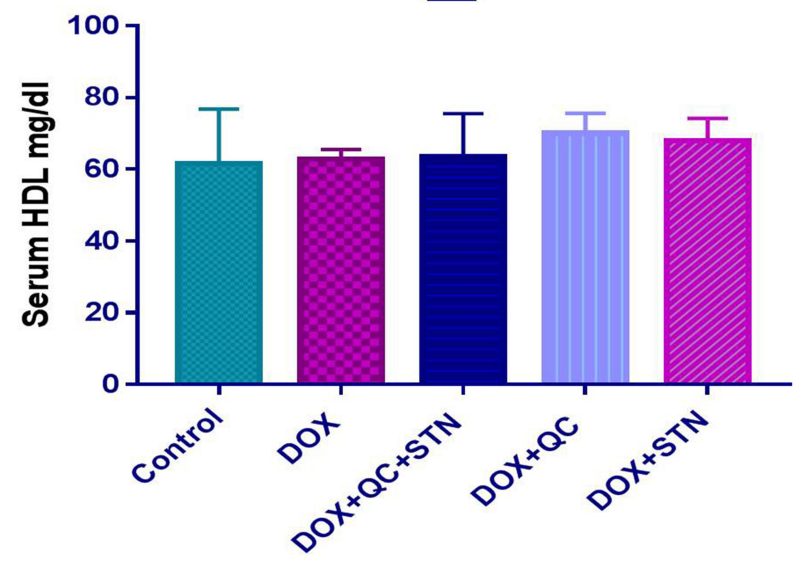

D

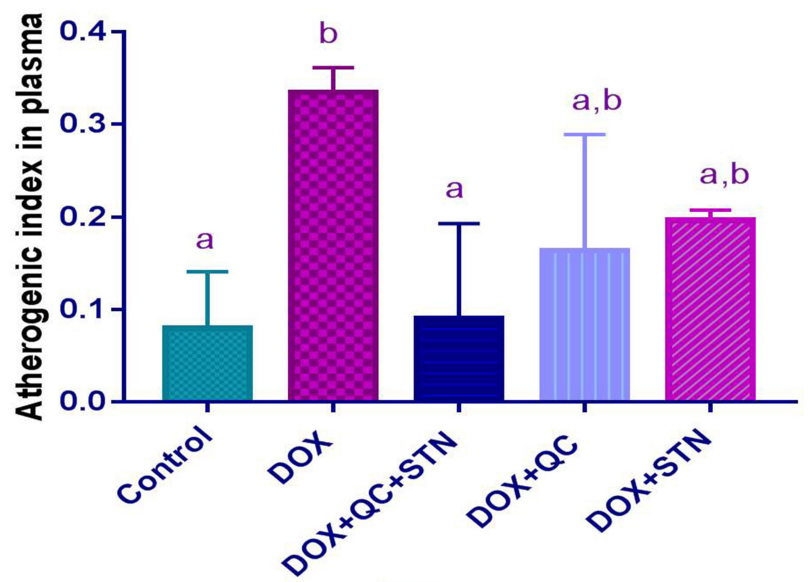

$\mathbf{F}$

Figure 3 Effect of quercetin and/or sitagliptin on serum lipid profile and atherogenic indices (A) total cholesterol, (B) LDL, (C) triglycerides, (D) HDL, (E) cardiac risk ratio and $(\mathbf{F})$ atherogenic index in plasma. Values were presented as mean \pm S.D ( $n=6$ animals in each group); values with non-identical letters (a, b, c) are significantly different using ANOVA and post hoc test $(p<0.05)$. 
( $P$-value $<0.001)$ increased by DOX compared to the control group (136 \pm 2 vs $72.33 \pm 4.3$ ). The combination of QC and STN resulted in a significant $(P$-value $=0.0004)$ decrease of TG level compared to DOX treated group $(77.5 \pm 2.5$ vs $136 \pm 2)$ (Figure 3C). Moreover, the HDL level was not affected by any of the treatments used in the study (Figure 3D). Regarding the atherogenic indices, DOX increased the cardiac risk ratio, however, this result was statistically not significant (Figure 3E), while the use of DOX resulted in a significant $(P$-value $=0.002)$ increase in the atherogenic index of plasma compared to the control group $(0.33 \pm 0.01$ vs $0.08 \pm 0.03)$. Furthermore, the combination of QC and STN significantly $(P$-value $=0.002)$ decreased the index compared to DOX treated group $(0.09 \pm 0.07$ vs $0.33 \pm 0.01)$ (Figure $3 F$ ).

\section{Histopathology Results}

Table 1 demonstrates the morphometric semiquantitative evaluation of heart sections, which shows a significant $\mathrm{P}<0.05$ reduction in the percentage of degenerative myocardial cells and inflammatory cells, together with a significant decrease in the area of fatty infiltration and vascular congestion in group $\mathrm{C}(\mathrm{DOX}+\mathrm{QC}+\mathrm{STN})$ in compare to group $\mathrm{B}$ (DOX group), which shows significant augmentation in the lesion severity. Furthermore, morphometric evaluation of histopathological lesions in group $\mathrm{D}$ and $\mathrm{E}(\mathrm{DOX}+\mathrm{QC})$ $(\mathrm{DOX}+\mathrm{STN})$, respectively, reveals significant $\mathrm{P}<0.05$ reduction in lesion severity as well, in comparison with group B. However, and as shown in Table 1, scoring and grading of lesion severity is significantly reduced in group $\mathrm{C}$ in comparison to groups $\mathrm{D}$ and $\mathrm{E}$ treatment animals. Furthermore, Figure 4 shows severe and diffuse infiltration of fat cells together with inflammatory cells within the heart parenchymal tissue in the DOX group (B) in comparison to the control group (A). On the other hand, the histopathological results of heart sections in all treatment groups display a significant reduction in lesion severity, evident by the decreased number of inflammatory and degenerative cells, together with the reduction of area of fatty infiltration and blood vessel congestion, yet it is more significant in group $\mathrm{C}(\mathrm{DOX}+\mathrm{QC}+\mathrm{STN})$ in comparison to other treatment groups as shown in Figure 4.

\section{Discussion}

The mechanism of doxorubicin-induced cardiotoxicity is still unclear and more likely to be multifactorial. ${ }^{23}$ One of the suggested mechanisms is a dysfunction of cardiac muscle that may end up with heart failure. ${ }^{24}$ Oxidative stress is another mechanism of DOX toxicity; damage of the myocardium by free radicals increases membrane permeability enhancing the release of LDH and CPK. ${ }^{25}$ In the current study, DOX increased the level of troponin, CPK, and LDH. Usually, during cardiac damage greater amount of troponin is released into the blood. ${ }^{26}$ Additionally, lactic acid dehydrogenase (LDH) is an enzyme that helps in producing energy; a high level of this enzyme is a biomarker for various diseases including CVDs. It presents in most of the tissues in the body and its level increase during cell injury. ${ }^{27}$ Another biomarker that increases during cardiac muscle injury or stress is $\mathrm{CPK}^{28}$ Each of QC and STN was effective in restoring troponin, CPK, and LDH levels to normal but the combination of both produced much more effects this could be attributed to the fact that the presence of two antioxidant agents ${ }^{29,30}$ may produce better results. ${ }^{14}$ The current study also revealed that DOX increased CRP and decreased TAOC when compared with the control group. It is clear that among the mechanisms of DOX toxicity are lipid peroxidation, oxidative damage, ${ }^{31}$ and inflammatory reaction, ${ }^{32}$ the use of QC and STN in combination produced more beneficial effects than the use of each alone

Table I Histological Semi-Quantitative Evaluation of Heart Lesions

\begin{tabular}{|c|c|c|c|c|c|c|}
\hline $\begin{array}{l}\text { Experimental Groups } \\
\mathrm{N}=5\end{array}$ & $\begin{array}{l}\text { Inflammatory } \\
\text { Cells (Mean \%)*** }\end{array}$ & $\begin{array}{c}\text { Fatty } \\
\text { Degeneration } \\
\text { (Mean \%) }\end{array}$ & $\begin{array}{c}\text { Fatty } \\
\text { Infiltration* } \\
\text { (Mean \%) }\end{array}$ & $\begin{array}{c}\text { Vascular } \\
\text { Congestion* } \\
\text { (Mean \%) }\end{array}$ & $\begin{array}{l}\text { Lesion } \\
\text { Scoring } \\
(0-100 \%)\end{array}$ & $\begin{array}{l}\text { Lesion } \\
\text { Grading }\end{array}$ \\
\hline (A) $\mathbf{C G}^{\dagger}$ & $2.8 \%{ }^{\mathrm{A} \#}$ & $4.2 \%^{\mathrm{A}}$ & $5.3 \%^{\mathrm{A}}$ & $4.7 \%^{\mathrm{A}}$ & $0-10 \%$ & No lesion \\
\hline (B) DOX & $83.7 \%^{\mathrm{D}}$ & $86.1 \%^{\mathrm{D}}$ & $92.6 \%^{\mathrm{E}}$ & $78.3 \%^{D}$ & $75-100 \%$ & Severe \\
\hline (C) DOX+QC+STN & $48.6 \%^{\mathrm{B}}$ & $46.2 \%^{B}$ & $43.8 \%^{\mathrm{B}}$ & $49.2 \%^{B}$ & $25-50 \%$ & Moderate \\
\hline (D) $D O X+Q C$ & $60.4 \%^{\mathrm{C}}$ & $59.5 \%^{C}$ & $56.8 \%^{C}$ & $71.4 \%^{c}$ & $50-75 \%$ & Moderate \\
\hline (E) DOX+STN & $55.8 \%^{C}$ & $57.4 \%^{\mathrm{C}}$ & $53.6 \%^{C}$ & $68.2 \%^{C}$ & $50-75 \%$ & Moderate \\
\hline
\end{tabular}

Notes: *Area of fatty infiltration and vascular congestion were estimated by $(\mu \mathrm{m})$. **Each value represents mean \pm SDM ( $\mathrm{n}=6)$. ${ }^{\#}$ Statistical comparison among groups: Mean values with different capital letters have significant differences at $(P<0.05)$. ${ }^{\dagger A}$ Control group; ${ }^{B}$ Doxorubicin group (DOX); ${ }^{C}$ Doxorubicin, Quercetin and Sitagliptin group $(\mathrm{DOX}+\mathrm{QC}+\mathrm{STN}) ;{ }^{\mathrm{D}}$ Doxorubicin and Quercetin group (DOX+QC); ${ }^{\mathrm{D} D o x o r u b i c i n}$ and Sitagliptin group (DOX+STN). 

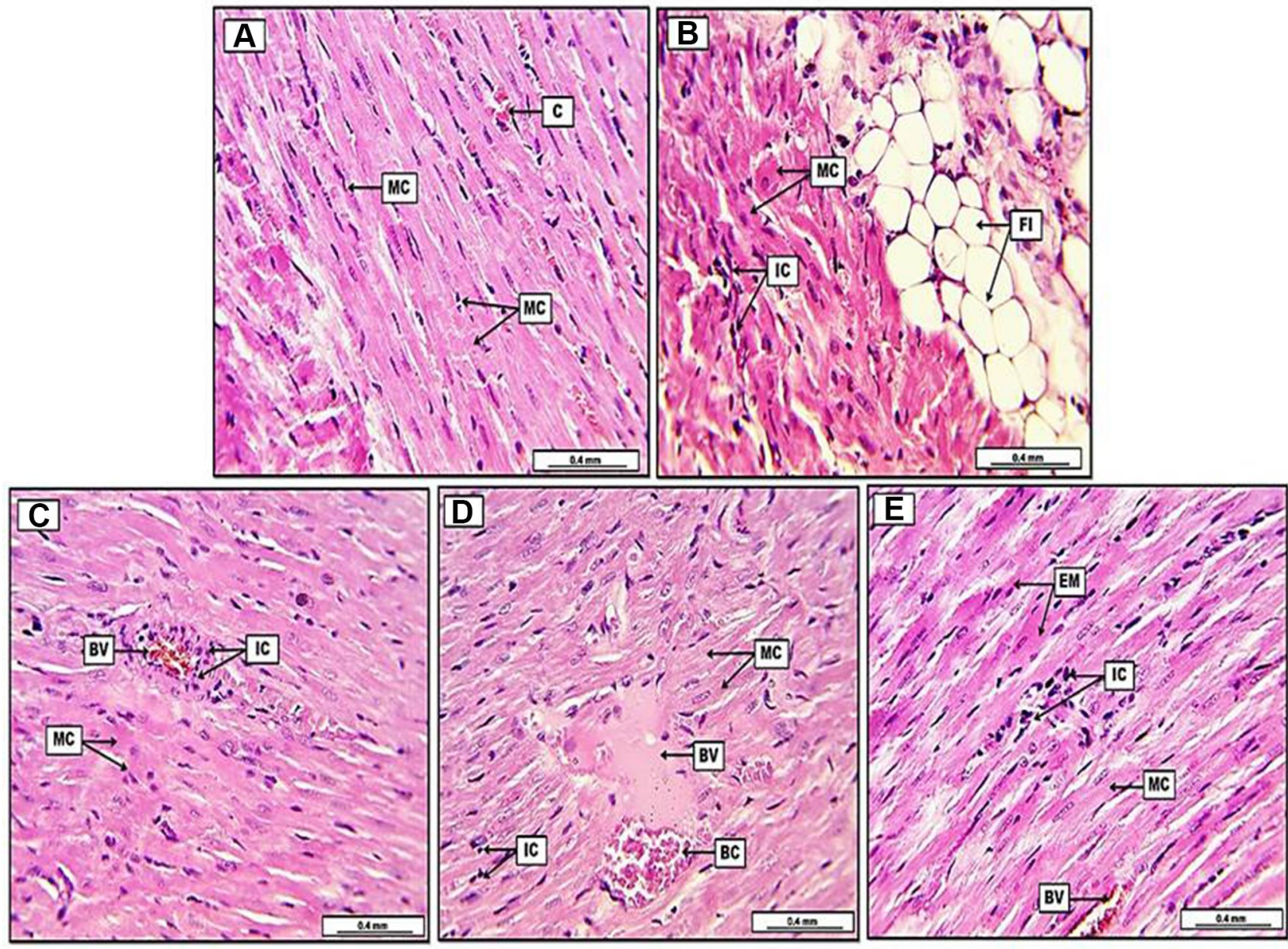

Figure 4 Photomicrograph of heart from groups; (A) control group, display typically arranged myocardial cells (MC), with their oval nuclei and light pinkish cytoplasm, in addition, the section shows some congested blood capillaries (C). (B) Doxorubicin group (DOX), reveal remarkable fatty infiltration (FI) within the cardiac muscle, together with significant fatty degeneration (FD), the section shows severe degenerative changes in myocardial muscle (MC), together with the infiltration of inflammatory cells (IC). (C) Doxorubicin, quercetin and sitagliptin group (DOX+QC+STN), display slight pre-vascular cuffing of inflammatory cells (IC), together with vascular congestion in some blood vessels (BV), moreover, some myocardial cells (MC) show acidophilic cytoplasm with condensate nuclei. (D) Doxorubicin and quercetin group (DOX+GC), demonstrate slight to moderate infiltration of inflammatory cells (IC), the section reveals some blood vessels (BV) with semi-coagulated red blood cells (BC) and eosinophilic plasma-rich protein. Myocardial muscle (MC) shows oval nuclei with cross-striated appearance. (E) Doxorubicin and sitagliptin group (DOX+STN), reveal slight infiltration of inflammatory cells (IC), the section shows some eosinophilic myocardial muscle cells (EM) with condensate nuclei, however, some other myocardial cells (MC) demonstrate typical cross striation together with their oval nuclei. Some blood vessels appear congested (BV). H\&E. Scale bars: $0.4 \mathrm{~mm}$.

and this result is in accordance with another study, ${ }^{33}$ and could be attributed to the protective effect of STN against oxidative stress through decreasing lipid peroxidation, ${ }^{34}$ furthermore, STN has been shown to ameliorate oxidative damage in experimental diabetic nephropathy. ${ }^{30}$ Additionally, the antioxidant capacity of the natural flavonol quercetin is well proved previously by minimizing free radical generation and enhancing the antioxidant system. QC alone was also effective in restoring TAOC and this result is also consistent with other studies. ${ }^{29,35}$ The antiinflammatory effect of quercetin has been proved in both animal and human studies, ${ }^{36}$ and STN has also been shown to downregulate some inflammatory pathways. ${ }^{37}$
Adding these effects together can explain the significant decrease in the level of CRP produced by the combination therapy.

Concerning the effect of DOX on lipid profile and atherogenic indices; the study revealed that DOX increased TG, LDL, and total cholesterol with no significant effect on HDL; this finding is in tune with other studies. $^{32,38,39}$ The combination of QC and STN was effective in attenuating the levels of LDL and TG. Quercetin alone was effective in ameliorating cholesterol levels. Other studies have shown the effectiveness of QC in minimizing dyslipidemia. ${ }^{40,41}$ Furthermore, DOX treatment increased the atherogenic index and this was 
decreased by the combination therapy. Sitagliptin in previous studies has proven to have anti-atherosclerotic activity related to its ability to decrease lipid accumulation, in addition to the antioxidant and anti-inflammatory activities that aid in inhibiting the progress of atherosclerosis. ${ }^{30,37}$ Quercetin also has been proven to inhibit LDL oxidation ${ }^{42}$ and protect against atherosclerosis, ${ }^{43}$ this can explain the effectiveness of the aforementioned combination in attenuating the atherogenic index and protecting the cardiac tissue from the deleterious effects of doxorubicin. Histopathological findings of the present study support the effectiveness of QC and STN together in reducing cardiac injury induced by DOX.

\section{Conclusion}

The results of the current study revealed the cardioprotective effects of each of quercetin and sitagliptin alone and proved that the combination of QC and STN was more effective in protecting the heart from the injury induced by DOX which could be attributed to the additive effects of this combination through antioxidant, anti-inflammatory, lipid lowering and anti-atherogenic activities; suggesting it as a good therapeutic candidate to be tested in the clinical setting.

\section{Acknowledgment}

The author appreciates the support of the College of Pharmacy, University of Sulaimani in providing facilities to accomplish this project.

\section{Disclosure}

The author reports no conflicts of interest in this work.

\section{References}

1. Shaito A, Thuan DTB, Phu HT, et al. Herbal medicine for cardiovascular diseases: efficacy, mechanisms, and safety. Front Pharmacol. 2020;11(April):1-32. doi:10.3389/fphar.2020.00422

2. Ferdinandy P, Baczkó I, Bencsik P, et al. Definition of hidden drug cardiotoxicity: paradigm change in cardiac safety testing and its clinical implications. Eur Heart J. 2019;40(22):1771-1777C. doi:10.1093/ eurheartj/ehy365

3. McGowan JV, Chung R, Maulik A, Piotrowska I, Walker JM, Yellon DM. Anthracycline chemotherapy and cardiotoxicity. Cardiovasc Drugs Ther. 2017;31(1):63-75. doi:10.1007/s10557-0166711-0

4. Nayebi M. Ultrastructural and echocardiographic assessment of chronic doxorubicin-induced cardiotoxicity in rats. Arch Razi Inst. 2020;75(1):56. doi:10.22092/ARI.2019.116862.1177

5. Thorn CF, Oshiro C, Marsh S, et al. Doxorubicin pathways. Pharmacogenet Genomics. 2011;21(7):440-446. doi:10.1097/ fpc.0b013e $32833 \mathrm{ffb} 56$
6. Reiner Ž, Laufs U, Cosentino F, Landmesser U. The year in cardiology 2018: prevention. Eur Heart J. 2019;40(4):336-344. doi:10.1093/eurheartj/ehy894

7. Singh S, Sedha S. Medicinal plants and their pharmacological aspects. FPI. 2018;1(4):156-170.

8. Varga E, Bodi A, Ferdinandy P, Droy-Lefaix MT, Blasig IE, Tosaki A. The protective effect of EGb 761 in isolated ischemic/ reperfused rat hearts: a link between cardiac function and nitric oxide production. J Cardiovasc Pharmacol. 1999;34(5):711-717. doi:10.1097/00005344-199911000-00013

9. Pataki T, Bak I, Kovacs P, Bagchi D, Das DK, Tosaki A. Grape seed proanthocyanidins improved cardiac recovery during reperfusion after ischemia in isolated rat hearts. Am J Clin Nutr. 2002;75 (5):894-899. doi:10.1093/ajcn/75.5.894

10. Bak I, Lekli I, Juhasz B, et al. Isolation and analysis of bioactive constituents of sour cherry (Prunus cerasus) seed kernel: an emerging functional food. J Med Food. 2010;13(4):905-910. doi:10.1089/jmf.2009.0188

11. Czompa A, Gyongyosi A, Czegledi A, et al. Cardioprotection afforded by sour cherry seed kernel: the role of heme oxygenase-1. $J$ Cardiovasc Pharmacol. 2014;64(5):412-419. doi:10.1097/ FJC.0000000000000132

12. Csiki Z, Papp-Bata A, Czompa A, et al. Orally delivered sour cherry seed extract (SCSE) affects cardiovascular and hematological parameters in humans. Phytother Res. 2015;29(3):444 449. doi:10.1002/ptr.5273

13. Jing Z, Wang Z, Li X, et al. Protective effect of quercetin on posttraumatic cardiac injury. Sci Rep. 2016;6(1):(February):1-10. doi:10.1038/srep30812

14. Shah P, Upaganlawar A, Balaraman R. Combined cardioprotective effects of quercetin and curcumin on doxorubicin induced cardiotoxicity in rats. Pharmacogn Mag. 2008;4(16SUPPL):246-250.

15. Zhou Y, Guo Z, Yan W, Wang W. Cardiovascular effects of sitagliptin - an anti-diabetes medicine. Clin Exp Pharmacol Physiol. 2018;45(7):628-635. doi:10.1111/1440-1681.12953

16. Garber AJ, Abrahamson MJ, Barzilay JI, et al. Consensus statement by the American association of clinical endocrinologists and American college of endocrinology on the comprehensive type 2 diabetes management algorithm - 2019 executive summary. Endocr Pract. 2019;25(1):69-100. doi:10.4158/CS-2018-0535

17. Green JB, Bethel MA, Armstrong PW, et al. Effect of sitagliptin on cardiovascular outcomes in type 2 diabetes. N Engl J Med. 2015;373 (3):232-242. doi:10.1056/nejmoa 1501352

18. Rehman MB, Tudrej BV, Soustre J, et al. Efficacy and safety of DPP-4 inhibitors in patients with type 2 diabetes: meta-analysis of placebo-controlled randomized clinical trials. Diabetes Metab. 2017;43(1):48-58. doi:10.1016/j.diabet.2016.09.005

19. Yang TY, Liaw YP, Huang JY, Chang HR, Chang KW, Ueng KC. Association of sitagliptin with cardiovascular outcome in diabetic patients: a nationwide cohort study. Acta Diabetol. 2016;53 (3):461-468. doi:10.1007/s00592-015-0817-x

20. Ahmed ZA, Abtar AN, Othman HH, Aziz TA. Effects of quercetin, sitagliptin alone or in combination in testicular toxicity induced by doxorubicin in rats. Drug Des Devel Ther. 2019;13 (September):3321-3329. doi:10.2147/DDDT.S222127

21. Bo MS, Cheah WL, Lwin S, Moe Nwe T, Win TT, Aung M. Understanding the relationship between atherogenic index of plasma and cardiovascular disease risk factors among staff of an university in Malaysia. J Nutr Metab. 2018;2018:2015. doi:10.1155/2018/7027624

22. Calling S, Johansson SE, Wolff M, Sundquist J, Sundquist K. The ratio of total cholesterol to high density lipoprotein cholesterol and myocardial infarction in women's health in the Lund area (WHILA): a 17-year follow-up cohort study. BMC Cardiovasc Disord. 2019;19 (1):1-9. doi:10.1186/s12872-019-1228-7

23. Rochette L, Guenancia C, Gudjoncik A, et al. Anthracyclines/trastuzumab: new aspects of cardiotoxicity and molecular mechanisms. Trends Pharmacol Sci. 2015;36(6):326-348. doi:10.1016/J.TIPS.2015.03.005 
24. Kelleni MT, Abdelbasset M. Drug induced cardiotoxicity: mechanism, prevention and management. Cardiotoxicity. 2018. doi:10.5772/ intechopen.79611

25. Viswanatha Swamy AHM, Wangikar U, Koti BC, Thippeswamy AHM, Ronad PM, Manjula DV. Cardioprotective effect of ascorbic acid on doxorubicin-induced myocardial toxicity in rats. Indian J Pharmacol. 2011;43(5):507-511. doi:10.4103/0253-7613.84952

26. Hasić S, Jadrić R, Kiseljaković E, Mornjaković Z, WinterhalterJadrić M. Troponin $\mathrm{T}$ and histological characteristics of rat myocardial infarction induced by isoproterenol. Bosn J BASIC Med Sci. 2007;7(3):212-217. doi:10.17305/bjbms.2007.3046

27. Kopel E, Kivity S, Morag-Koren N, Segev S, Sidi Y. Relation of serum lactate dehydrogenase to coronary artery disease. Am J Cardiol. 2012;110(12):1717-1722. doi:10.1016/j.amjcard.2012.08.005

28. Jensen DM. Approach to asymptomatic creatine kinase elevation. Physiol Behav. 2018;176(1):1570-1573. doi:10.1038/s41395-018-0061-4

29. Zhang M, Swarts SG, Yin L, et al. Antioxidant properties of quercetin. In: Advances in Experimental Medicine and Biology. Vol. 701. 2011: 283-289. doi:10.1007/978-1-4419-7756-4 38

30. Civantos E, Bosch E, Ramirez E, et al. Sitagliptin ameliorates oxidative stress in experimental diabetic nephropathy by diminishing the miR-200a/Keap-1/Nrf2 antioxidant pathway. Diabetes Metab Syndr Obes. 2017;10:207-222. doi:10.2147/DMSO.S132537

31. Hrelia S, Fiorentini D, Maraldi T, et al. Doxorubicin induces early lipid peroxidation associated with changes in glucose transport in cultured cardiomyocytes. Biochim Biophys Acta. 2002;1567 (SUPPL):150-156. doi:10.1016/S0005-2736(02)00612-0

32. Arunachalam S, Tirupathi Pichiah PB, Achiraman S. Doxorubicin treatment inhibits PPAR $\gamma$ and may induce lipotoxicity by mimicking a type 2 diabetes-like condition in rodent models. FEBS Lett. 2013;587(2):105-110. doi:10.1016/j.febslet.2012.11.019

33. Eitah HE, Maklad YA, Abdelkader NF, Gamal El Din AA, Badawi MA, Kenawy SA. Modulating impacts of quercetin/sitagliptin combination on streptozotocin-induced diabetes mellitus in rats. Toxicol Appl Pharmacol. 2019;365:30-40. doi:10.1016/J.TAAP.2018.12.011

34. Nuransoy A, Beytur A, Polat A, Samdanci E, Sagir M, Parlakpinar H. Renal failure protective effect of sitagliptin against renal ischemia reperfusion injury in rats protective effect of sitagliptin against renal ischemia reperfusion injury in rats. Ren Fail. 2015;37(4):687-693. doi:10.3109/0886022X.2015.1010991
35. D'Andrea G. Quercetin: a flavonol with multifaceted therapeutic applications? Fitoterapia. 2015;106:256-271. doi:10.1016/j. fitote. 2015.09 .018

36. Chen S, Jiang H, Wu X, Fang J. Therapeutic effects of quercetin on inflammation, obesity, and type 2 diabetes. Mediators Inflamm. 2016;2016(Article ID 9340637):5. doi:10.1155/2016/9340637

37. Majeed SA, Hadi NR, Al Mudhafar AM, Al-Janabi HA. Sitagliptin ameliorates the progression of atherosclerosis via down regulation of the inflammatory and oxidative pathways. SAGE Open Med. 2013;1:205031211349991. doi:10.1177/2050312113499912

38. Nayagam AAJ, Gunasekaran S, Rangarajan S, Muthaiah S. Myocardial potency of Caesalpinia bonducella Linn. on doxorubicin induced myocardial infarction in albino rats. Clin Phytoscience. 2019;5(1). doi:10.1186/s40816-019-0146-7

39. Chennuru A, Saleem MTS. Antioxidant, lipid lowering, and membrane stabilization effect of sesamol against doxorubicin-induced cardiomyopathy in experimental rats. Biomed Res Int. 2013;2013:934239. doi:10.1155/2013/934239

40. Derakhshanian H, Djalali M, Djazayery A, et al. Quercetin ameliorates lipid and apolipoprotein profile in high-dose glucocorticoid treated rats. Arq Bras Cardiol. 2020;115(1):102-108. doi:10.36660/ abc. 20180397

41. Huang H, Liao D, Dong Y, Pu R. Effect of quercetin supplementation on plasma lipid profiles, blood pressure, and glucose levels: a systematic review and meta-analysis. Nutr Rev. 2020;78 (8):615-626. doi:10.1093/nutrit/nuz071

42. Patel RV, Mistry BM, Shinde SK, Syed R, Singh V, Shin HS. Therapeutic potential of quercetin as a cardiovascular agent. Eur J Med Chem. 2018;155:889-904. doi:10.1016/j.ejmech.2018.06.053

43. Jia Q, Cao H, Shen D, et al. Quercetin protects against atherosclerosis by regulating the expression of PCSK9, CD36, PPAR $\gamma, \mathrm{LXR} \alpha$ and ABCA1. Int J Mol Med. 2019;44(3):893-902. doi:10.3892/ijmm.2019.4263

\section{Publish your work in this journal}

Cancer Management and Research is an international, peer-reviewed open access journal focusing on cancer research and the optimal use of preventative and integrated treatment interventions to achieve improved outcomes, enhanced survival and quality of life for the cancer patient.
The manuscript management system is completely online and includes a very quick and fair peer-review system, which is all easy to use. Visit http://www.dovepress.com/testimonials.php to read real quotes from published authors. 